\title{
Comparison of zotarolimus-eluting and sirolimus- eluting coronary stents: a study from the Western Denmark Heart Registry
}

Michael Maeng ${ }^{1 *}$, Lisette Okkels Jensen ${ }^{2}$, Anne Kaltoft ${ }^{1}$, Hans-Henrik Tilsted ${ }^{3}$, Evald Høj Christiansen ${ }^{1}$, Per Thayssen², Morten Madsen ${ }^{4}$, Henrik Toft Sørensen ${ }^{4,5}$, Jens Flensted Lassen ${ }^{1}$ and Leif Thuesen ${ }^{1}$

\begin{abstract}
Background: We evaluated the effectiveness and safety of a zotarolimus-eluting (ZES) versus a sirolimus-eluting (SES) coronary stent in a large cohort of patients treated with one of these stents in Western Denmark.

Methods: A total of 6,122 patients treated with ZES $(n=2,282)$ or SES $(n=3,840)$ were followed for up to 27 months. We ascertained clinical outcomes based on national medical databases.

Results: Incidence of target lesion revascularization (no. per 100 person-years) was 5.3 in the ZES group compared to 1.9 in the SES group (adjusted hazard ratio $(H R)=2.19,95 \%$ confidence intervals $(\mathrm{Cl})$ : $1.39-3.47 ; p=0.001$ ). All-cause mortality was also higher in the ZES group (ZES: 6.3; SES: 3.3; adjusted HR=1.34, 95\% Cl: 1.05-1.72; $p=0.02$ ), while stent thrombosis (ZES: 1.2; SES: 0.5 ; adjusted HR=1.98, 95\% Cl: $0.75-5.23 ; p=0.14$ ) did not differ significantly.
\end{abstract}

Conclusions: In agreement with previously published randomised data, this observational study indicated that the ZES was associated with an increased risk of death and TLR in a large cohort of consecutive patients.

Keywords: Zotarolimus, Sirolimus, Stent, Mortality, Stent thrombosis, Diabetes mellitus

\section{Background}

Introduction of first-generation drug-eluting stents (DESs) more than halved the need for target lesion revascularization (TLR) after coronary stent implantation [1-6]. However, safety concerns have been raised about the first-generation DESs, especially regarding an increased risk of late stent thrombosis ( $>30$ days after stent implantation) [4,7]. The effective inhibition of instent neointima formation by the first-generation DESs may reduce neointimal coverage of stents, leaving stent struts as a nidus for late stent thrombosis. Late stent thrombosis has also been associated with late-acquired malapposition of stent struts [8] and late vascular inflammation (beyond that associated with the initial vascular injury and subsequent healing) [9], both of which

\footnotetext{
* Correspondence: michael.maeng@ki.au.dk

'Department of Cardiology, Aarhus University Hospital, Skejby,

Brendstrupgaardsvej 100, 8200 Aarhus N, Denmark

Full list of author information is available at the end of the article
}

may be related to either the type of drug eluted or the polymer coating of the stents.

Since the second-generation fast-release zotarolimuseluting Endeavor ${ }^{\mathrm{TM}}$ stent (ZES) has been shown to induce relatively uniform and complete neointimal coverage of the stent struts and to have a lower incidence of late-acquired incomplete stent apposition [10,11], it could represent a safer alternative to the first-generation DESs [12]. Also, the phosphorylcholine coating used for drug-elution from the ZES could be a safer noninflammatory alternative to the polymers used for sirolimus-eluting and paclitaxel-eluting stents $[13,14]$.

In the current study, based on data from the Western Denmark Heart Registry (WDHR), we used the sirolimuseluting Cypher $^{\mathrm{TM}}$ stent (SES) as the comparator stent. Intravascular ultrasound and angiography studies have shown that the SES reduced angiographic late lumen loss and neointima formation assessed by intravascular ultrasound to a level below detection with these modalities [1,15-17]. Preclinical studies showed that 
both ZES and SES were associated with delayed endothelialisation in a rabbit model [18], and that ZES had a higher grade of inflammation than SES at 30 days but less inflammation at 90 and 180 days in a porcine model [19]. Findings from randomised studies, the largest being the Danish Organisation for Randomized Trials with Clinical Outcome (SORT OUT) III trial, indicated that ZES, as compared to SES, had lower efficacy

Table 1 Patient and procedure characteristics of patients treated with zotarolimus-eluting (ZES) or sirolimuseluting stents (SES)

\begin{tabular}{|c|c|c|c|}
\hline & ZES $N=2,282$ & SES $N=3,840$ & $P$ \\
\hline $\operatorname{Age}^{*}$ & $\begin{array}{l}67(59-75) \\
\text { years }\end{array}$ & $\begin{array}{l}65(57-73) \\
\text { years }\end{array}$ & $<0.000$ \\
\hline Male gender & $1,645(72 \%)$ & $2,869(75 \%)$ & 0.024 \\
\hline Family history & 807 (44\%) & $1,455(46 \%)$ & 0.17 \\
\hline Smoking & $592(34 \%)$ & $1,121(37 \%)$ & 0.039 \\
\hline Diabetes mellitus & $342(15 \%)$ & $602(16 \%)$ & 0.41 \\
\hline Hypertension & 999 (54\%) & $1,573(49 \%)$ & 0.001 \\
\hline $\begin{array}{l}\text { Previous coronary } \\
\text { artery } \\
\text { bypass operation }\end{array}$ & $173(9 \%)$ & $279(9 \%)$ & 0.53 \\
\hline $\begin{array}{l}\text { Previous percutaneous } \\
\text { coronary intervention }\end{array}$ & 735 (34\%) & $1,184(32 \%)$ & 0.25 \\
\hline $\begin{array}{l}\text { Previous myocardial } \\
\text { infarction }\end{array}$ & 793 (37\%) & $1,268(35 \%)$ & 0.20 \\
\hline $\begin{array}{l}\text { Lipid lowering } \\
\text { treatment }\end{array}$ & $1,217(66 \%)$ & $1,995(63 \%)$ & 0.027 \\
\hline Procedure time ${ }^{*}$ & $23(15-36) \min$ & $21(14-34) \min$ & 0.0007 \\
\hline $\begin{array}{l}\text { Use of GPIlb/IIla } \\
\text { inhibitors }\end{array}$ & $626(27 \%)$ & 1143 (30\%) & 0.051 \\
\hline $\begin{array}{l}\text { Number of treated } \\
\text { lesions* }\end{array}$ & $1(1-2)$ & $1(1-2)$ & 0.175 \\
\hline Number of stents $>1$ & $514(22.5 \%)$ & $771(20.1 \%)$ & 0.023 \\
\hline Total stent length* & $\begin{array}{l}18.0 \\
(14.0-24.0) \mathrm{mm}\end{array}$ & $\begin{array}{l}18.0 \\
(13.0-26.0) \mathrm{mm}\end{array}$ & 0.070 \\
\hline
\end{tabular}

Indication for

percutaneous coronary intervention

\begin{tabular}{|c|c|c|c|}
\hline Stable angina pectoris & $924(41 \%)$ & $1,610(42 \%)$ & \\
\hline $\begin{array}{l}\text { Unstable angina } \\
\text { pectoris/non } \\
\text { ST-segment elevation } \\
\text { myocardial infarction }\end{array}$ & 763 (33\%) & $1,158(30 \%)$ & \\
\hline $\begin{array}{l}\text { ST-segment elevation } \\
\text { myocardial infarction }\end{array}$ & $511(22 \%)$ & $946(25 \%)$ & \\
\hline Other & $84(4 \%)$ & $126(3 \%)$ & \\
\hline $\begin{array}{l}\text { harlson's comorbidity } \\
\text { ndex score }\end{array}$ & & & 0.0003 \\
\hline 0 & $1,368(60 \%)$ & 2,475 (65\%) & \\
\hline $1-2$ & 725 (32\%) & $1,125(29 \%)$ & \\
\hline $3+$ & $189(8 \%)$ & $230(6 \%)$ & \\
\hline
\end{tabular}

* Median (25\%-75\% quartiles). and was associated with increased risk of early stent thrombosis and all-cause mortality. As the external validity of randomised trials is limited by selection bias, it is important that data from randomised trials can be reproduced in observational studies [20]. The present study used the WDHR to compare ZES and SES in order to see if the randomised SORT OUT III data could be confirmed in a large cohort of consecutive patients.

\section{Methods}

Data extraction

Data for this population-based cohort study were obtained from the WDHR and national databases. The WDHR contains patient- and procedure-specific information on coronary interventions performed at the three coronary intervention centers in Western Denmark (Aarhus University Hospital, Skejby, Aarhus University Hospital, Aalborg, and Odense University Hospital). The national databases used in the study included the Danish Civil Registration System, the National Registry of Causes of Death, and the Danish National Registry of Patients, all of which cover the entire region's population (approximately 3 million inhabitants, $55 \%$ of the Danish population). A detailed description of these databases has been published previously [21].

Between August 1, 2005 and October 1, 2007 10,992 patients were treated with percutaneous coronary intervention (PCI) in the region covered by the WDHR. The study cohort consisted of 6,122 (56\%) patients with

Table 2 Lesion characteristics of patients treated with zotarolimus-eluting (ZES) or sirolimus-eluting (SES) stents

\begin{tabular}{|c|c|c|c|}
\hline & $\begin{array}{l}\text { ZES N }=3,090 \\
\text { lesions }\end{array}$ & $\begin{array}{l}\text { SES N }=5,095 \\
\text { lesions }\end{array}$ & $P$ Value \\
\hline Vessel & & & $<0.0001$ \\
\hline LM & 99 (3.2\%) & $158(3.1 \%)$ & \\
\hline $\mathrm{LAD}$ & $1,255(41 \%)$ & $2,388(47 \%)$ & \\
\hline LCX & $743(24 \%)$ & $1,154(23 \%)$ & \\
\hline $\mathrm{RCA}$ & 991 (32\%) & $1394(27 \%)$ & \\
\hline Sapheneous vein graft & $36(0.9 \%)$ & $44(1.2 \%)$ & 0.18 \\
\hline Restenotic lesion & $87(2.8 \%)$ & $74(1.5 \%)$ & $<0.0001$ \\
\hline Stent thrombosis lesion & $28(0.9 \%)$ & $24(0.5 \%)$ & 0.0076 \\
\hline Lesion length* & $12(10-20) \mathrm{mm}$ & $15(10-20) \mathrm{mm}$ & 0.027 \\
\hline Lesion type & & & 0.0008 \\
\hline A & $659(21 \%)$ & $1,100(22 \%)$ & \\
\hline B1 & $823(27 \%)$ & $1,542(30 \%)$ & \\
\hline B2 & $629(20 \%)$ & $1,014(20 \%)$ & \\
\hline C & $979(32 \%)$ & $1,439(28 \%)$ & \\
\hline Stent length ${ }^{\dagger}$ & $19.9 \pm 11.9 \mathrm{~mm}$ & $20.2 \pm 11.9 \mathrm{~mm}$ & $<0.0001$ \\
\hline Number of stents $>1$ & $581(18.8 \%)$ & $837(16.4 \%)$ & 0.006 \\
\hline
\end{tabular}


successful implantation of either the ZES (Endeavor, Medtronic, Santa Rosa, Ca) or the SES (Cypher Select or Cypher Select+; Cordis, Johnson \& Johnson, Warren, NJ). For each patient we included only the first PCI procedure performed during the study period (the index procedure). Other drug-eluting stents or a combination of ZES/SES/other stents were utilized in 1,050 patients (10\%), bare metal stents in 2,125 patients (19\%), and balloon angioplasty or other interventions in 1,695 patients (15\%). One-third of the patients included in the present study $(n=1,868 ; 31 \%)$ were randomised to ZES or SES as part of the SORT OUT III study, which enrolled patients between January 2006 and August 2007.
Post-PCI antiplatelet regimens included lifelong acetylsalicylic acid (75 mg daily) and clopidogrel with a loading dose of $300 \mathrm{mg}$ or $600 \mathrm{mg}$ followed by $75 \mathrm{mg}$ daily. The recommended duration of clopidogrel treatment was 12 months during the entire study period.

The effectiveness parameter was clinically driven TLR, defined as any PCI including the stent or within $5 \mathrm{~mm}$ from the proximal or distal stent edge). Safety parameters included all-cause mortality, cardiac mortality, late myocardial infarction ( $\mathrm{MI} ;>30$ days), and definite stent thrombosis.

We used the Academic Research Consortium definition of definite stent thrombosis [22]. We defined new

Table 3 Hazard ratio (HR) estimates of adverse events among patients treated with zotarolimus-eluting stents (ZES) or sirolimus-eluting stents (SES) in western denmark, August 2005 to October 2007

\begin{tabular}{|c|c|c|c|c|c|c|c|}
\hline \multirow[t]{2}{*}{ Endpoint } & \multirow[t]{2}{*}{ Period (days) } & \multicolumn{2}{|c|}{ Patients with ZES } & \multicolumn{2}{|c|}{ Patients with SES } & \multirow{2}{*}{$\begin{array}{c}\text { Adjusted HR* } \\
(95 \% \mathrm{Cl})\end{array}$} & \multirow[t]{2}{*}{$P$ Value } \\
\hline & & No. of events & $\begin{array}{c}\text { No./100 } \\
\text { person-year }\end{array}$ & No. of events & $\begin{array}{c}\text { No./100 } \\
\text { person-year }\end{array}$ & & \\
\hline \multicolumn{2}{|l|}{ Patient level analysis } & \multicolumn{2}{|c|}{$N=2,282$} & \multicolumn{2}{|c|}{$N=3,840$} & & \\
\hline \multirow[t]{4}{*}{ Death } & $0-823$ & 135 & 6.3 & 159 & 3.3 & $1.35(1.05-1.73)$ & 0.018 \\
\hline & $0-30$ & 57 & 31.0 & 50 & 16.0 & $1.66(1.10-2.50)$ & 0.016 \\
\hline & $31-365$ & 62 & 4.1 & 70 & 2.4 & $1.19(0.82-1.73)$ & 0.388 \\
\hline & $366-823$ & 16 & 3.5 & 39 & 2.5 & $1.26(0.67-2.34)$ & 0.475 \\
\hline \multirow[t]{4}{*}{ Cardiac death } & $0-823$ & 57 & 2.7 & 59 & 1.2 & $1.33(0.89-2.00)$ & 0.183 \\
\hline & $0-30$ & 32 & 17.4 & 29 & 9.3 & $1.39(0.80-2.41)$ & 0.229 \\
\hline & $31-365$ & 21 & 1.4 & 23 & 0.8 & $1.17(0.59-2.32)$ & 0.711 \\
\hline & $366-823$ & 4 & 0.9 & 7 & 0.4 & $1.36(0.31-5.95)$ & 0.687 \\
\hline \multirow[t]{4}{*}{ Noncardiac death } & $0-823$ & 53 & 2.5 & 66 & 1.4 & 1.27 (0.87-1.87) & 0.217 \\
\hline & $0-30$ & 16 & 8.7 & 20 & 6.4 & $1.32(0.65-2.66)$ & 0.467 \\
\hline & $31-365$ & 31 & 2.1 & 34 & 2.1 & $1.25(0.75-2.09)$ & 0.397 \\
\hline & $366-823$ & 6 & 1.3 & 12 & 0.8 & $1.39(0.50-3.89)$ & 0.532 \\
\hline \multirow[t]{2}{*}{ Myocardial infarction } & $31-823$ & 66 & 3.5 & 108 & 2.5 & $0.98(0.69-1.42)$ & 0.964 \\
\hline & $366-823$ & 9 & 2.1 & 30 & 2.0 & $0.99(0.43-2.28)$ & 0.992 \\
\hline $\begin{array}{l}\text { Target lesion } \\
\text { revascularization }\end{array}$ & $0-823$ & 110 & 5.3 & 91 & 1.9 & $2.16(1.36-3.42)$ & 0.001 \\
\hline \multirow[t]{4}{*}{ Stent thrombosis } & $0-823$ & 26 & 1.2 & 24 & 0.5 & $2.01(0.76-5.34)$ & 0.159 \\
\hline & $0-30$ & 21 & 11.5 & 13 & 4.2 & $3.62(0.92-14.2)$ & 0.065 \\
\hline & $31-365$ & 4 & 0.3 & 5 & 0.2 & $1.17(0.18-7.39)$ & 0.870 \\
\hline & $366-823$ & 1 & 0.2 & 6 & 0.4 & Not calculable & - \\
\hline Lesion level analysis & & \multicolumn{2}{|c|}{$N=3,090$} & \multicolumn{2}{|c|}{$N=5,095$} & & \\
\hline Target lesion revascularization & $0-823$ & 115 & 4.0 & 96 & 1.5 & $2.48(1.87-3.27)$ & $<0.0001$ \\
\hline \multirow[t]{4}{*}{ Stent thrombosis } & $0-823$ & 28 & 1.0 & 24 & 0.4 & $2.21(1.26-3.87)$ & 0.006 \\
\hline & $0-30$ & 23 & 9.3 & 13 & 3.1 & $2.75(1.38-5.47)$ & 0.004 \\
\hline & $31-365$ & 4 & 0.2 & 5 & 0.1 & $1.47(0.39-5.57)$ & 0.568 \\
\hline & $366-823$ & 1 & 0.2 & 6 & 0.3 & $1.22(0.14-10.9)$ & 0.857 \\
\hline
\end{tabular}

*The patient level analyses were adjusted for age, sex, Charlson Comorbidity score, diabetes mellitus, PCI indication, procedure time, no. of treated lesions, total stent length, and total no. of stents. The lesion level analyses were adjusted for age, sex, diabetes mellitus, PCI indication, procedure time, and stent length.

${ }^{\dagger}$ Defined as late (>30 days) definite stent thrombosis, myocardial infarction, or death from any cause. 
MIs as hospitalization for MI occurring $>30$ days after the index PCI [23] based on admissions and readmissions for MI (ICD-10 codes I21-I21.9) identified from the Danish National Registry of Patients [21]. We used the original death certificates obtained from the National Registry of Cause of Deaths to classify deaths according to their underlying cause [21]. We ascertained all repeat coronary interventions (including balloon angioplasty, stent implantation, and coronary artery bypass grafting) from the WDHR. These re-interventions were divided into target vessel revascularization (TVR) and non-TVR. An endpoint committee examined all TVRs and identified all TLRs. Subsequently, all TLRs caused by stent thrombosis were identified by review of the angiogram and patient files, and the clinical presentation of these stent thromboses was identified and classified as STEMI, nonSTEMI, unstable angina pectoris, or stable angina pectoris.

We retrieved data from the WDHR on potential predictors of subsequent cardiovascular events, including patient, procedure, and lesion characteristics. We also obtained the complete hospitalization history since 1977 for each patient from the Danish National Registry of Patients until the date of stent implantation, and computed the patients' Charlson Comorbidity Index scores, based on 19 major disease categories [24].

\section{Statistical analysis}

We computed Aalen-Nelson curves for patients and lesions and used the life-table method to compute the cumulative incidence of each outcome. We used Cox proportional hazard regression to compute HRs as a measure of the relative risks for each outcome. Since the hazards were not proportional throughout the follow-up period, we computed HR estimates within separate time windows, for which the proportionality assumption held. The HRs in these sub-analyses reflected the risk among patients alive and at risk of a given outcome at the start of each time period. In regression analyses at the patient level, we controlled for age, sex, Charlson Comorbidity Index score (3 comorbidity levels), diabetes mellitus, PCI indication (STEMI, nonSTEMI/unstable angina pectoris, stable angina pectoris, or other), procedure time, number of lesions treated, total stent length (i.e., the combined length of stents in all treated lesions), and total number of stents implanted. In the lesion-specific analyses (stent thrombosis and TLR) we adjusted for age, sex, diabetes mellitus, PCI indication, procedure time, and stent length (i.e., the combined length of stents used to treat a specific lesion). The subgroup analyses of patients with and without diabetes were controlled for the same parameters except diabetes.

Depending on whether data conformed to a normal distribution, continuous variables were compared by use of the two-sample $t$-test or the Mann-Whitney test. Categorical variables were compared using the chi-square test. We used SAS software version 9.2 (SAS Institute Inc., Cary, NC, USA) to analyse the data.

\section{Results}

Among patients included in this study, 2,282 patients with 3,090 lesions were treated with ZES and 3,840 patients with 5,095 lesions received SES. All patients were followed to November 10, 2007, i.e.,. for at least 40 days and up to a maximum of 823 days). The average follow-up time was 411 days (ZES: 342 days; SES: 452 days). Data on cause of death were not available for 59 patients.

Baseline patient and procedure characteristics presented in Table 1, and lesion characteristics presented in Table 2, showed differences between the ZES and SES groups. The most important were older age, longer procedure times, higher comorbidity scores, and differences regarding vessel and lesion types in the ZES group.

The outcome data are provided in Table 3 and the main outcomes are depicted in Figures 1 and 2. TLR (5.3\% vs. $1.9 \%$; adjusted hazard ratio [HR] $2.16,95 \%$ confidence intervals [CI $1.36-3.42 ; p=0.001$ ) was more than twice as common in the ZES group at the patient level, a finding confirmed at the lesion level of analysis. The safety parameters of all-cause mortality $(6.3 \%$ vs. $3.3 \%$; adjusted HR 1.35, 95\% CI 1.05-173; $p=0.018$ ), stent thrombosis at the lesion level $(1.0 \%$ vs. $0.4 \%$; adjusted HR 2.21, 95\% CI 1.26-3.87; $p=0.006$ ), but not

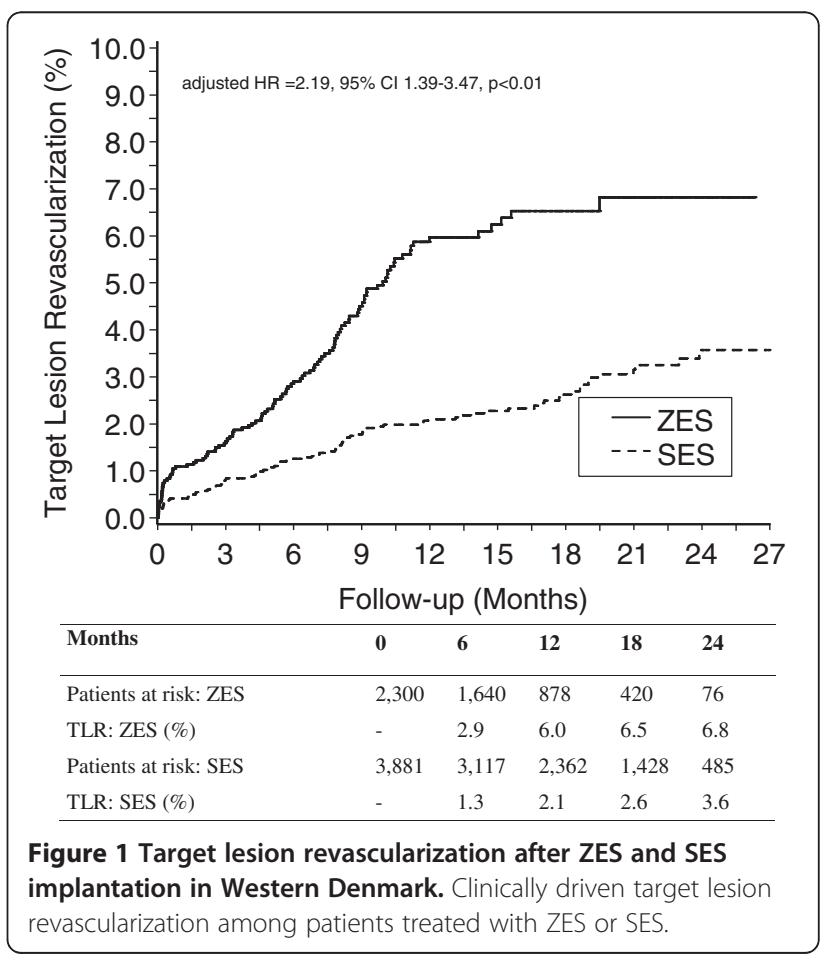



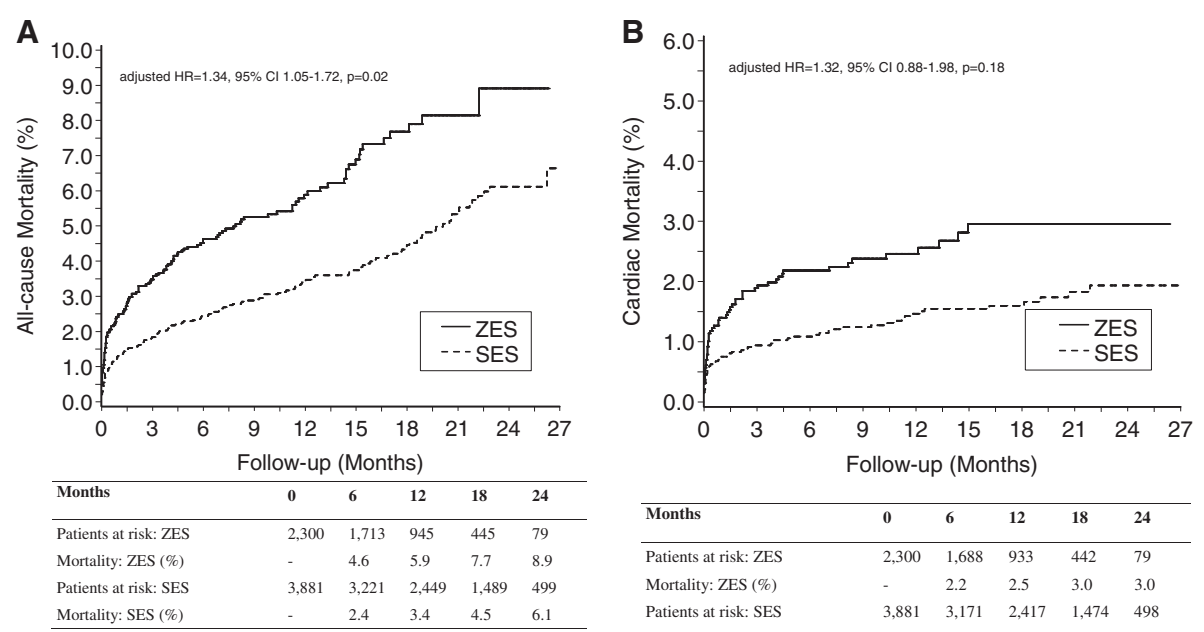

\begin{tabular}{llllll}
\hline Months & $\mathbf{0}$ & $\mathbf{6}$ & $\mathbf{1 2}$ & $\mathbf{1 8}$ & $\mathbf{2 4}$ \\
\hline Patients at risk: ZES & 2,300 & 1,688 & 933 & 442 & 79 \\
Mortality: ZES (\%) & - & 2.2 & 2.5 & 3.0 & 3.0 \\
Patients at risk: SES & 3,881 & 3,171 & 2,417 & 1,474 & 498 \\
Mortality: SES (\%) & - & 1.1 & 1.5 & 1.6 & 1.9 \\
\hline
\end{tabular}
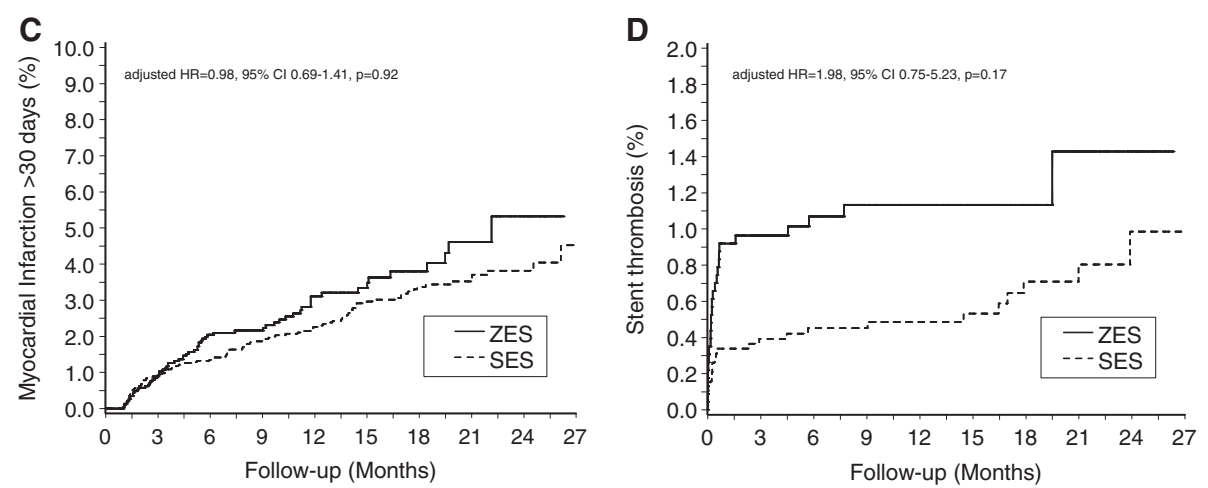

\begin{tabular}{llllll}
\hline Months & $\mathbf{1}$ & $\mathbf{6}$ & $\mathbf{1 2}$ & $\mathbf{1 8}$ & $\mathbf{2 4}$ \\
\hline Patients at risk: ZES & 2,158 & 1,654 & 904 & 427 & 75 \\
MI: ZES (\%) & - & 2.1 & 3.2 & 3.9 & 5.4 \\
Patients at risk: SES & 3,687 & 3,113 & 2,360 & 1,421 & 479 \\
MI: SES (\%) & - & 1.4 & 2.3 & 3.4 & 3.8 \\
\hline
\end{tabular}

\begin{tabular}{llllll}
\hline Months & $\mathbf{0}$ & $\mathbf{6}$ & $\mathbf{1 2}$ & $\mathbf{1 8}$ & $\mathbf{2 4}$ \\
\hline Patients at risk: ZES & 2,300 & 1,667 & 920 & 437 & 77 \\
Stent thrombosis: ZES (\%) & - & 1.1 & 1.1 & 1.1 & 1.4 \\
Patients at risk: SES & 3,881 & 3,141 & 2,402 & 1,462 & 494 \\
Stent thrombosis: SES (\%) & - & 0.5 & 0.5 & 0.7 & 1.0 \\
\hline
\end{tabular}

Figure 2 Safety Outcomes of ZES and SES in the Western Denmark Heart Registry. Risk of all-cause mortality (A), cardiac mortality (B), late (>30 days) myocardial infarction (C), and stent thrombosis (D) among patients treated with ZES or SES.

stent thrombosis at the patient level $(1.2 \%$ vs. $0.5 \%$; adjusted HR 2.01, 95\% CI 0.76-5.34; $p=0.159)$ were increased in the ZES group as compared to the SES group. This was apparently due to an excess of both early (day 0 to 30 ) mortality and early stent thrombosis. There were no significant differences between the two groups in late safety parameters (day 31 to 823 ).

Outcomes stratified by presence/absence of diabetes are presented in Table 4. Patients without diabetes treated with a ZES had increased risk of target lesion revascularization (TLR; $4.6 \%$ vs. $2.0 \%$; HR $2.14,95 \%$ CI $1.29-3.54 ; p=0.0032)$ and early definite stent thrombosis at the lesion level (3.4\% vs. 1.4\%; HR 1.97, 95\% CI 1.113.48, $\mathrm{p}=0.0202$ ). All other assessed parameters did not differ significantly. Patients with diabetes treated with a ZES had increased risk of death $(9.9 \%$ vs. $4.6 \%$, adjusted HR 2.03, 95\% CI 1.21-3.42; $p=0.0076)$, cardiac death (5.4\% vs. 1.5\%; adjusted HR 3.54, 95\% CI 1.59-7.90; $p=0.0020)$, and TLR (9.8\% vs. $1.8 \%$; adjusted HR 3.64, 95\% CI 1.10-12.1; $p=0.0350)$. Lesion level analyses confirmed the findings for TLR and indicated a higher risk of stent thrombosis in the ZES group.

Stent thrombosis accounted for 50 of the 202 TLRs. These patients were admitted due to ST-segment elevation myocardial infarction [STEMI; $\mathrm{n}=39$ (78.0\%)], nonSTEMI $[\mathrm{n}=6(12.0 \%)]$, and unstable angina pectoris $[\mathrm{n}=5(10.0 \%)]$.

\section{Discussion}

The SORT OUT III trial reported that the ZES was inferior to SES regarding both efficacy and safety [25]. Although we attempted to randomise routine clinical care patients ("all-comers") in SORT OUT III, we reported that the separate group of patients that were eligible, but for different reasons not randomised, had higher 30-day mortality than patients who entered the 
Table 4 Hazard ratio (hr) estimates of adverse events among patients with and without diabetes treated with cypher or endeavour stents

\begin{tabular}{|c|c|c|c|c|c|c|c|c|c|}
\hline \multirow{2}{*}{$\begin{array}{l}\text { Endpoint } \\
\text { (no(no/person year)) }\end{array}$} & \multirow[t]{2}{*}{ Period (days) } & \multicolumn{2}{|c|}{ Diabetic patients } & \multirow{2}{*}{$\begin{array}{l}\text { Adjusted } \mathrm{HR}^{*} \\
(95 \% \mathrm{Cl})\end{array}$} & \multirow[t]{2}{*}{$P$ value } & \multicolumn{2}{|c|}{ Non diabetic patients } & \multirow{2}{*}{$\begin{array}{l}\text { Adjusted HR* } \\
(95 \% \mathrm{Cl})\end{array}$} & \multirow[t]{2}{*}{$P$ value } \\
\hline & & Endeavour & Cypher & & & Endeavour & Cypher & & \\
\hline Patient level analysis* & & $N=342$ & $N=602$ & & & $N=1936$ & $N=3207$ & & \\
\hline \multirow[t]{3}{*}{ Death } & $0-823$ & $31(9.9)$ & $36(4.6)$ & $2.03(1.21-3.42)$ & 0.0076 & $102(5.6)$ & $122(3.2)$ & $1.20(0.90-1.60)$ & 0.20 \\
\hline & $0-30$ & $12(43.9)$ & $10(20.5)$ & $2.13(0.88-5.15)$ & 0.0942 & $43(27.5)$ & $40(15.3)$ & $1.52(0.96-2.42)$ & 0.077 \\
\hline & $31-365$ & $15(6.9)$ & $18(3.9)$ & $1.69(0.80-3.58)$ & 0.1701 & $47(3.7)$ & $51(2.1)$ & $1.09(0.71-1.68)$ & 0.70 \\
\hline \multirow[t]{3}{*}{ Cardiac death } & $0-823$ & $17(5.4)$ & $12(1.5)$ & $3.54(1.59-7.90)$ & 0.0020 & $38(2.1)$ & $46(1.2)$ & $0.97(0.60-1.58)$ & 0.91 \\
\hline & $0-30$ & $8(29.3)$ & $4(8.2)$ & $3.71(1.03-13.4)$ & 0.0449 & $22(14.1)$ & $25(29.6)$ & $1.09(0.58-2.03)$ & 0.79 \\
\hline & $31-365$ & $8(3.7)$ & $7(1.5)$ & $3.38(1.10-10.4)$ & 0.0341 & $13(1.0)$ & $15(0.6)$ & $0.70(0.29-1.72)$ & 0.44 \\
\hline \multirow[t]{3}{*}{ Noncardiac death } & $0-823$ & $12(3.8)$ & $14(1.8)$ & $1.65(0.72-3.79)$ & 0.2347 & $41(2.3)$ & $52(1,3)$ & $1.19(0.77-1.83)$ & 0.44 \\
\hline & $0-30$ & $4(14.6)$ & $6(12.3)$ & $1.22(0.32-4.61)$ & 0.7678 & $12(7.7)$ & $14(5.4)$ & $1.30(0.56-3.02)$ & 0.55 \\
\hline & $31-365$ & $7(3.2)$ & $7(1.5)$ & $1.67(0.51-5.44)$ & 0.3984 & $24(1.9)$ & $27(1.1)$ & $1.18(0.66-2.10)$ & 0.57 \\
\hline \multirow[t]{3}{*}{ Myocardial infarction } & $30-823$ & $54(19.6)$ & $86(12.7)$ & $1.24(0.86-1.79)$ & 0.2522 & $319(20.4)$ & $543(16.4)$ & $0.98(0.85-1.13)$ & 0.79 \\
\hline & $0-30$ & $41(168)$ & $68(155)$ & $1.24(0.82-1.86)$ & 0.3032 & $279(206)$ & $473(210)$ & $0.99(0.85-1.16)$ & 0.92 \\
\hline & $31-365$ & $10(5.2)$ & $14(3.5)$ & $0.89(0.33-2.40)$ & 0.8195 & $35(3.2)$ & $49(2.4)$ & $0.93(0.56-1.55)$ & 0.79 \\
\hline $\begin{array}{l}\text { Composite safety } \\
\text { end point }{ }^{\dagger}\end{array}$ & $30-823$ & $31(11.1)$ & $48(6.8)$ & $1.45(0.87-2.40)$ & 0.1507 & $105(6.5)$ & $168(4.7)$ & $1.00(0.76-1.31)$ & 0.98 \\
\hline $\begin{array}{l}\text { Target lesion } \\
\text { revascularization }\end{array}$ & $0-823$ & $29(9.8)$ & $14(1.8)$ & $3.64(1.10-12.1)$ & 0.0350 & $81(4.6)$ & $76(2.0)$ & $2.14(1.29-3.54)$ & 0.003 \\
\hline In-stent restenosis & $0-823$ & $24(8.0)$ & $11(1.4)$ & $7.18(1.59-32.4)$ & 0.0103 & $60(3.4)$ & $56(1.4)$ & $1.97(1.11-3.48)$ & 0.020 \\
\hline \multirow[t]{4}{*}{ Stent thrombosis } & $0-823$ & $5(1.6)$ & $4(0.5)$ & - & - & $21(1.2)$ & $20(0.5)$ & $2.92(0.95-8.93)$ & 0.060 \\
\hline & $0-30$ & $4(14.7)$ & $1(2.0)$ & - & - & $17(10.9)$ & $12(4.6)$ & $5.61(1.14-27.6)$ & 0.034 \\
\hline & $31-365$ & $1(0.5)$ & $1(0.2)$ & - & - & $3(0.2)$ & $4(0.2)$ & $1.74(0.23-13.2)$ & 0.59 \\
\hline & $366-823$ & $0(0.0)$ & $2(0.8)$ & - & - & $1(0.3)$ & $40.3)$ & - & - \\
\hline \multicolumn{10}{|l|}{ Lesion level analysis } \\
\hline $\begin{array}{l}\text { Target lesion } \\
\text { revascularization }\end{array}$ & $0-823$ & $29(7.3)$ & $15(1.4)$ & $5.06(2.65-9.69)$ & $<.0001$ & $86(3.5)$ & $80(1.5)$ & $2.08(1.53-2.85)$ & $<0.0001$ \\
\hline In-stent restenosis & $0-823$ & $24(6.0)$ & $12(1.1)$ & $5.06(2.48-10.3)$ & $<.0001$ & $63(2.5)$ & $60(1.2)$ & $2.08(1.45-2.99)$ & $<0.0001$ \\
\hline \multirow[t]{4}{*}{ Stent thrombosis } & $0-823$ & $5(1.2)$ & $4(0.4)$ & $4.33(1.02-18.4)$ & 0.047 & $23(0.9)$ & $20(0.4)$ & $2.03(1.10-3.76)$ & 0.0234 \\
\hline & $0-30$ & $4(11.2)$ & $1(1.5)$ & $11.6(1.10-122)$ & 0.0413 & $19(9.0)$ & $12(3.5)$ & $2.40(1.15-4.99)$ & 0.0194 \\
\hline & $31-365$ & $1(0.4)$ & $1(0.2)$ & $1.84(0.11-30.5)$ & 0.6693 & $3(0.2)$ & $4(0.1)$ & $1.34(0.29-6.08)$ & 0.7074 \\
\hline & $366-823$ & $0(0.0)$ & $2(0.5)$ & - & - & $1(0.2)$ & $4(0.2)$ & $1.68(0.17-16.4)$ & 0.66 \\
\hline
\end{tabular}

* The patient level analyses were adjusted for age, sex, Charlson Comorbidity score, PCl indication, procedure time, no. of treated lesions, total stent length, and total no. of stents. The lesion level analyses were adjusted for age, sex, $\mathrm{PCl}$ indication, procedure time, and stent length.

† Defined as late (>30 days) definite stent thrombosis, myocardial infarction, or death from any cause.

trial $(3 \%$ vs. $<1 \%)$. It is therefore of clinical importance to confirm the generalizability of the SORT OUT III trial by examination of the entire cohort of patients treated with a ZES or SES in Western Denmark. Our data confirm and extend the SORT OUT III results to all patients treated with ZES and SES in Western Denmark. As in the SORT OUT III trial, we found that compared with the SES, use of the ZES increased all-cause mortality, and produced twice as high rates of TLR and definite stent thrombosis at medium-term follow-up.

The finding that ZES has higher TLR rates than SES is concurrent with efficacy analyses based on intravascular ultrasound [11], optical coherence tomography [26], angiography [27], and with clinical results reported from a Swedish registry [28], a large Korean randomised comparison [29], a Korean randomised study in patients with ST-segment elevation [30], a German randomised study [31], and the SORT OUT III trial [25]. Although carefully performed analyses have shown that late lumen loss detected by angiography predicted ISR and TLR [32-34], it has been suggested that minor late loss differences in the lower end of the late loss scale may not lead to TLR differences [12,34]. Based on the current data, the reported in-stent late loss difference between the 
two stents seems large enough to produce a significant difference in clinically driven TLR.

Definite stent thrombosis constituted $25 \%$ of all TLRs, caused MI in $90 \%$ of patients experiencing this adverse event, and was the cause of all but one TLR-related STEMI. Even though TLR was a relatively rare event in the present cohort, definite stent thrombosis was a relatively frequent and high-risk cause of TLR. ZES was associated with higher rates of definite stent thrombosis and death during the first 30 days after implantation whereas we found no overall differences between the two study stents in late safety outcomes from day 31 on. In comparison to SES and other available drug-eluting stents, it is possible that the rapid elution of zotarolimus from the phosphorylcholine coating creates a milieu in the stented arterial wall that facilitates early stent thrombosis and thus explains the reported increased risk of early stent thrombosis $[25,29]$. This hypothesis is supported by preclinical data describing more vascular inflammation with the ZES than the SES at 30 days [19]. With regard to very late ( $>1$ year) stent thrombosis, the phosphorylcholine coating and the larger neointima formation by the ZES may still reduce the risk of this adverse event when dual antiplatelet therapy is limited to aspirin only, but our current comparison to SES is inconclusive on this issue. A recent study by Serruys et al [35]. showed that a modified slow-release zotarolimuseluting stent (the Resolute ${ }^{\mathrm{TM}}$ stent) was non-inferior to an everolimus-eluting stent. It may thus be release kinetics rather than type of drug that explains the clinical differences between ZES and SES implantation.

Patients with diabetes have a higher risk of adverse events after PCI, which includes an increased rate of TLR due to excessive neointima formation in diabetic patients [36]. Our results confirm this hypothesis. In comparison to SES, we found that ZES-treated patients without diabetes had a 2.1-fold higher risk of TLR while ZES-treated diabetic patients had a 3.6-fold higher risk. These results accord with results from a Swedish registry and a small randomized trial [28,37]. Efficacy differences between various DESs may thus be amplified in diabetic patients.

Our risk estimates are based on population-based data, largely ruling out referral and diagnostic biases. Adjustment for a broad range of important prognostic cardiovascular factors and the fact that $31 \%$ of patients were randomised to the study stent are likely to have reduced the risk of any major uncontrolled or residual confounding. Although our study is still limited by potential confounding by indication due to lack of randomization of the majority of patients, the strength of this study is that the results are consistent with the randomised SORT OUT III. The clinical outcome data were ascertained by use of registry data. In this regard it is important that the study was performed in a small
European country with a stable population and an accurate registration of the vital status and cause of death of its citizens. All contacts with the Danish healthcare system are registered, allowing 100\% follow-up. Underreporting of events (such as MIs or TLRs during visits abroad) and misclassifications are possible, but unlikely to have a major impact on our results, and equally unlikely to favour one of the two study stents. Another consideration is that the study's follow-up time was too short to fully quantify possible risks. It is possible that longer follow-up would yield different long-term safety profiles for the two drug-eluting stents. Moreover, our results with the fast-release Endeavor ${ }^{\mathrm{TM}}$ ZES cannot be extrapolated to the newer slow-release Resolute ${ }^{\mathrm{TM}} \mathrm{ZES}$ [35]. Finally, we do not have data on the duration of dual anti-platelet treatment for the two groups, which theoretically might have affected the results.

\section{Conclusions}

We conclude that this observational study found that ZES is inferior to SES, thereby extending randomised results to a large cohort of consecutive patients.

\section{Abbreviation}

Cl: Confidence interval; DES: Drug-eluting stent; HR: Hazard ratio; MI: Myocardial infarction; PCl: Percutaneous coronary intervention; SES: Sirolimus-eluting stent; SORT OUT: DaniSh Organisation for Randomised Trials with Clinical OUTcome; STEMI: ST-segment elevation Ml; TLR: Target lesion revascularization; TVR: Target vessel revascularization; WDHR: Western Denmark Heart Registry; ZES: Zotarolimus-eluting stent.

\section{Competing interests}

Medtronic and Cordis have both supported research at the three departments of cardiology in Aalborg, Skejby, and Odense through unrestricted research grants.

\section{Authors' contributions}

MiM was responsible for the conception and design of the study. All authors except MoM and HTS contributed to the review of clinical events. MoM and HTS was responsible for the statistical analysis. MiM drafted the manuscript. All authors read and approved the final manuscript.

\section{Funding}

This is an academic study financed by the three university hospitals that enrolled the patients.

\section{Author details}

'Department of Cardiology, Aarhus University Hospital, Skejby, Brendstrupgaardsvej 100, 8200 Aarhus N, Denmark. ${ }^{2}$ Department of Cardiology, Odense University Hospital, Odense, Denmark. ${ }^{3}$ Department of Cardiology, Aarhus University Hospital, Aalborg Hospital, Aalborg, Denmark. ${ }^{4}$ Department of Clinical Epidemiology, Aarhus University Hospital, Aarhus, Denmark. ${ }^{5}$ Department of Epidemiology, Boston University, Boston, MA, USA.

Received: 22 January 2012 Accepted: 20 September 2012 Published: 2 October 2012

\section{References}

1. Moses JW, Leon MB, Popma JJ, Fitzgerald PJ, Holmes DR, O'Shaughnessy C, et al: Sirolimus-eluting stents versus standard stents in patients with stenosis in a native coronary artery. N Engl J Med 2003, 349:1315-1323.

2. Stone GW, Ellis SG, Cox DA, Hermiller J, O'Shaughnessy C, Mann JT, et al: A polymer-based, paclitaxel-eluting stent in patients with coronary artery disease. N Engl J Med 2004, 350:221-231. 
3. Kelbaek H, Klovgaard L, Helqvist S, Lassen JF, Krusell LR, Engstrom T, et al: Long-term outcome in patients treated with sirolimus-eluting stents in complex coronary artery lesions: 3 -year results of the SCANDSTENT (Stenting Coronary Arteries in Non-Stress/Benestent Disease) trial. J Am Coll Cardiol 2008, 51:2011-2016.

4. Kaltoft A, Jensen LO, Maeng M, Tilsted HH, Thayssen P, Bottcher M, et al: Two-Year Clinical Outcomes after Implantation of Coronary Sirolimusand Paclitaxel-eluting Stents and Bare Metal Stents in Western Denmark. J Am Coll Cardiol 2008, 53:658-664.

5. Mauri L, Silbaugh TS, Wolf RE, Zelevinsky K, Lovett A, Zhou Z, et al: Longterm clinical outcomes after drug-eluting and bare-metal stenting in massachusetts. Circulation 2008, 118:1817-1827.

6. Tu JV, Bowen J, Chiu M, Ko DT, Austin PC, He Y, et al: Effectiveness and safety of drug-eluting stents in Ontario. N Engl J Med 2007, 357:1393-1402.

7. Daemen J, Wenaweser P, Tsuchida K, Abrecht L, Vaina S, Morger C, et al: Early and late coronary stent thrombosis of sirolimus-eluting and paclitaxel-eluting stents in routine clinical practice: data from a large two-institutional cohort study. Lancet 2007, 369:667-678.

8. Cook S, Wenaweser P, Togni M, Billinger M, Morger C, Seiler C, et al: Incomplete stent apposition and very late stent thrombosis after drug-eluting stent implantation. Circulation 2007, 115:2426-2434.

9. Finn AV, Nakazawa G, Joner M, Kolodgie FD, Mont EK, Gold HK, et al: Vascular responses to drug eluting stents: importance of delayed healing. Arterioscler Thromb Vasc Biol 2007, 27:1500-1510.

10. Sakurai $R$, Hongo $Y$, Yamasaki M, Honda $Y$, Bonneau HN, Yock PG, et al: Detailed intravascular ultrasound analysis of Zotarolimus-eluting phosphorylcholine-coated cobalt-chromium alloy stent in de novo coronary lesions (results from the ENDEAVOR II trial). Am J Cardiol 2007, 100:818-823.

11. Miyazawa A, Ako J, Hongo Y, Hur SH, Tsujino I, Courtney BK, et al: Comparison of vascular response to zotarolimus-eluting stent versus sirolimus-eluting stent: intravascular ultrasound results from ENDEAVOR III. Am Heart J 2008, 155:108-113.

12. Pinto Slottow TL, Waksman R: Overview of the 2007 Food and Drug Administration Circulatory System Devices Panel meeting on the endeavor zotarolimus-eluting coronary stent. Circulation 2008, 117:1603-1608

13. Lewis AL, Tolhurst LA, Stratford PW: Analysis of a phosphorylcholine-based polymer coating on a coronary stent pre- and post-implantation. Biomaterials 2002, 23:1697-1706.

14. Maeng M, Jensen LO, Falk E, Andersen HR, Thuesen L: Negative vascular remodelling after implantation of bioabsorbable magnesium alloy stents in porcine coronary arteries: a randomised comparison with bare-metal and sirolimus-eluting stents. Heart 2009, 95:241-246.

15. Maeng M, Jensen LO, Galloe AM, Thayssen P, Christiansen EH, Hansen KN, et al: Comparison of the sirolimus-eluting versus paclitaxel-eluting coronary stent in patients with diabetes mellitus: the diabetes and drug-eluting stent (DiabeDES) randomized angiography trial. Am J Cardiol 2009, 103:345-349.

16. Jensen LO, Maeng M, Thayssen P, Christiansen EH, Hansen KN, Galloe A, et al: Neointimal hyperplasia after sirolimus-eluting and paclitaxel-eluting stent implantation in diabetic patients: The Randomized Diabetes and Drug-Eluting Stent (DiabeDES) Intravascular Ultrasound Trial. Eur Heart $J$ 2008, 29:2733-2741.

17. Dibra A, Kastrati A, Mehilli J, Pache J, Sch hlen H, von Beckerath N, et al: Paclitaxel-eluting or Sirolimus-eluting stents to prevent restenosis in diabetic patients. N Engl J Med 2005, 353:663-670.

18. Joner M, Nakazawa G, Finn AV, Quee SC, Coleman L, Acampado E, et al: Endothelial cell recovery between comparator polymer-based drugeluting stents. J Am Coll Cardiol 2008, 52:333-342.

19. Nakazawa G, Finn AV, John MC, Kolodgie FD, Virmani R: The significance of preclinical evaluation of sirolimus-, paclitaxel-, and zotarolimus-eluting stents. Am J Cardiol 2007, 100:36M-44M.

20. Sørensen HT, Lash TL, Rothman KJ: Beyond randomized controlled trials: a critical comparison of trials with nonrandomized studies. Hepatology 2006, 44:1075-1082

21. Jensen LO, Maeng M, Kaltoft A, Thayssen P, Hansen HH, Bottcher M, et al: Stent thrombosis, myocardial infarction, and death after drug-eluting and bare-metal stent coronary interventions. J Am Coll Cardiol 2007, 50:463-470
22. Mauri L, Hsieh WH, Massaro JM, Ho KK, D’Agostino R, Cutlip DE: Stent thrombosis in randomized clinical trials of drug-eluting stents. $N$ Engl J Med 2007, 356:1020-1029.

23. Tunstall-Pedoe H, Kuulasmaa K, Amouyel P, Arveiler D, Rajakangas AM, Pajak A: Myocardial infarction and coronary deaths in the World Health Organization MONICA Project. Registration procedures, event rates, and case-fatality rates in 38 populations from 21 countries in four continents. Circulation 1994, 90:583-612.

24. Charlson ME, Pompei P, Ales KL, MacKenzie CR: A new method of classifying prognostic comorbidity in longitudinal studies: development and validation. J Chronic Dis 1987, 40:373-383.

25. Rasmussen K, Maeng M, Kaltoft A, Thayssen P, Kelbaek H, Tilsted HH, et al: Efficacy and safety of zotarolimus-eluting and sirolimus-eluting coronary stents in routine clinical care (SORT OUT III): a randomised controlled superiority trial. Lancet 2010, 375:1090-1099.

26. Kim JS, Jang IK, Kim JS, Kim TH, Takano M, Kume T, et al: Optical coherence tomography evaluation of zotarolimus-eluting stents at 9-month follow-up: comparison with sirolimus-eluting stents. Heart 2009, 95:1907-1912.

27. Kandzari DE, Leon MB, Popma JJ, Fitzgerald PJ, O'Shaughnessy C, Ball MW, et al: Comparison of zotarolimus-eluting and sirolimus-eluting stents in patients with native coronary artery disease: a randomized controlled trial. J Am Coll Cardiol 2006, 48:2440-2447

28. Frobert O, Lagerqvist B, Carlsson J, Lindback J, Stenestrand U, James SK: Differences in restenosis rate with different drug-eluting stents in patients with and without diabetes mellitus: a report from the SCAAR (Swedish Angiography and Angioplasty Registry). J Am Coll Cardiol 2009, 53:1660-1667.

29. Park DW, Kim YH, Yun SC, Kang SJ, Lee SW, Lee CW, et al: Comparison of zotarolimus-eluting stents with sirolimus- and paclitaxel-eluting stents for coronary revascularization: the ZEST (comparison of the efficacy and safety of zotarolimus-eluting stent with sirolimus-eluting and paclitaxeleluting stent for coronary lesions) randomized trial. J Am Coll Cardiol 2010, 56:1187-1195.

30. Lee CW, Park DW, Lee SH, Kim YH, Hong MK, Kim JJ, et al: Comparison of the efficacy and safety of zotarolimus-, sirolimus-, and paclitaxel-eluting stents in patients with ST-elevation myocardial infarction. Am J Cardiol 2009, 104:1370-1376.

31. Byrne RA, Mehilli J, lijima R, Schulz S, Pache J, Seyfarth M, et al: A polymerfree dual drug-eluting stent in patients with coronary artery disease: a randomized trial vs. polymer-based drug-eluting stents. Eur Heart J 2009 30:923-931.

32. Mauri L, Orav EJ, Kuntz RE: Late loss in lumen diameter and binary restenosis for drug-eluting stent comparison. Circulation 2005, 111:3435-3442.

33. Mauri L, Orav EJ, Candia SC, Cutlip DE, Kuntz RE: Robustness of late lumen loss in discriminating drug-eluting stents across variable observational and randomized trials. Circulation 2005, 112:2833-2839.

34. Pocock SJ, Lansky AJ, Mehran R, Popma JJ, Fahy MP, Na Y, et al: Angiographic surrogate end points in drug-eluting stent trials: a systematic evaluation based on individual patient data from 11 randomized, controlled trials. J Am Coll Cardiol 2008, 51:23-32.

35. Serruys PW, Silber S, Garg S, van Geuns RJ, Richardt G, Buszman PE, et al: Comparison of zotarolimus-eluting and everolimus-eluting coronary stents. N Engl J Med 2010, 363:136-146.

36. Jensen LO, Maeng M, Thayssen P, Kaltoft A, Tilsted HH, Lassen JF, et al: Long-term outcomes after percutaneous coronary intervention in patients with and without diabetes mellitus in Western Denmark. Am J Cardiol 2010, 105:1513-1519.

37. Briguori C, Airoldi F, Visconti G, Focaccio A, Caiazzo G, Golia B, et al: Novel Approaches for Preventing or Limiting Events in Diabetic Patients (Naples-Diabetes) Trial: A Randomized Comparison of 3 Drug-Eluting Stents in Diabetic Patients. Circ Cardiovasc Interv 2011, 4:121-129.

doi:10.1186/1471-2261-12-84

Cite this article as: Maeng et al:: Comparison of zotarolimus-eluting and sirolimus-eluting coronary stents: a study from the Western Denmark Heart Registry. BMC Cardiovascular Disorders 2012 12:84. 